DOI: https://doi.org/10.15688/re.volsu.2019.1.3

UDC 332.122

Submitted: 05.01.2019

LBC 65.04

Accepted: 04.02.2019

\title{
METHODOLOGICAL APPROACHES TO REGIONS' TYPOLOGY FOR WORKING OUT THE STRATEGY OF RUSSIA'S SPATIAL DEVELOPMENT
}

\author{
Andrey O. Polynev \\ Russian Foreign Trade Academy at the Ministry of Economic Development of the Russian Federation, \\ Moscow, Russian Federation; \\ Russian Presidential Academy of National Economy and Public Administration, Moscow, Russian Federation
}

\section{Irina V. Grishina}

Russian Foreign Trade Academy at the Ministry of Economic Development of the Russian Federation, Moscow, Russian Federation;

Russian Presidential Academy of National Economy and Public Administration, Moscow, Russian Federation

\begin{abstract}
The article is dedicated to the overview of new methodological approaches towards the typology of Russian regions developed to support the locality-based decisions at the federal level of governance in order to design and implement the Spatial Development Strategy of the Russian Federation in the long-term. Drawing evidence from several examples illustrating the formation of different regional typologies the authors propose their own one taking into the account the core principles of Russian State Regional Policy and the aims of Spatial Development Strategy which were formulated in its Conception. Giving the current conditions which indicate a necessity for a radical improvement of spatial development governance system, the research proposes a number of criteria towards the typology of Russian regions. The authors propose the measures for the system of criteria for social and economic indicators that can be used to generate homogeneous groups of regions on the basis of subdividing the regions under analysis into corresponding groups within the development of sectoral and industrial or problem focuses typology. For the creation of a structural and sectoral typology of the regions, the indices of the share of specific types of the economic activity in the structure of GDP in the total volume of the shipped goods into the manufacturing plants are used. The results of such a 2D-typology of Russian regions when using a structural, industrial and problem-focused typologies made on the basis of the official statistical data issued by the Rosstat over the period 2014-2016 are provided. The main approaches to their use at the determination of priorities of perspective social and economic development of the regions of the Russian Federation are given.

Key words: regions'typology, spatial development strategy, evaluation criteria, evaluation algorithm, methodological approach.

Citation. Polynev A.O., Grishina I.V. Methodological Approaches to Regions’ Typology for Working out the Strategy of Russia's Spatial Development. Regionalnaya ekonomika. Yug Rossii [Regional Economy. The South of Russia], 2019, vol. 7, no. 1, pp. 29-41. (in Russian). DOI: https://doi.org/10.15688/re.volsu.2019.1.3
\end{abstract}

УДК 332.122

Дата поступления статьи: 05.01.2019

ББК 65.04

Дата принятия статьи: 04.02.2019

\section{МЕТОДИЧЕСКИЕ ПОДХОДЫ К ПОСТРОЕНИЮ ТИПОЛОГИИ РЕГИОНОВ ДЛЯ РАЗРАБОТКИ СТРАТЕГИИ ПРОСТРАНСТВЕННОГО РАЗВИТИЯ РОССИИ}

\author{
Андрей Олегович Полынев
}

Всероссийская академия внешней торговли Минэкономразвития России, г. Москва, Российская Федерация; Российская академия народного хозяйства и государственной службы, г. Москва, Российская Федерация

(С) Полынев А.О., Гришина И.В., 2019 


\section{Ирина Владимировна Гришина}

Всероссийская академия внешней торговли Минэкономразвития России, г. Москва, Российская Федерация; Российская академия народного хозяйства и государственной службы, г. Москва, Российская Федерация

Аннотация. В статье представлены методические подходы к построению типологии регионов (субъектов Российской Федерации), обеспечивающей поддержку принятия территориально-ориентированных управленческих решений на федеральном уровне в рамках разработки и реализации Стратегии пространственного развития Российской Федерации на долгосрочную перспективу. Отмечены примеры из отечественного опыта исследований в области типологизации российских регионов с учетом общих принципов государственной региональной политики, а также построения различного рода целевых типологий. Изложены основополагающие факторы, обусловливающие необходимость кардинального совершенствования системы управления пространственным развитием страны.

Разработаны предложения по системе критериальных экономических индикаторов, которые могут быть использованы для формирования группировок субъектов Российской Федерации на основе отнесения анализируемых регионов к соответствующим типологическим группам в рамках разработки структурно-отраслевой и проблемно-ориентированной типологий.

Для построения структурно-отраслевой типологии регионов используются показатели доли отдельных видов экономической деятельности в структуре ВРП и в общем объеме отгруженных товаров обрабатывающих производств, проблемно-ориентированной - показатели среднедушевого ВРП (с учетом уровня покупательной способности), плотности населения, а также ряд индикаторов, отражающих уровень накопленного экономического потенциала.

Приводятся результаты построения двухмерной группировки российских регионов на базе их структурноотраслевой и проблемно-ориентированной типологий, выполненных на основе отчетных данных Росстата за 20142016 гг., изложены основные подходы к их использованию при определении приоритетов перспективного социально-экономического развития субъектов Российской Федерации.

Ключевые слова: типология регионов, стратегия пространственного развития, критерии оценки, алгоритм оценки, методический подход.

Цитирование. Полынев А. О., Гришина И. В. Методические подходы к построению типологии регионов для разработки стратегии пространственного развития России // Региональная экономика. Юг России. 2019. Т. 7 , № 1. C. 29-41. DOI: https://doi.org/10.15688/re.volsu.2019.1.3

\section{Постановка проблемы}

Совершенствование социально-экономического развития России, активизация и укрепление межрегиональных связей, создание пространственной среды, благоприятной для жизнедеятельности людей, формирования и преумножения человеческого капитала, обусловливают необходимость наиболее полного использования накопленного экономического потенциала и имеющихся конкурентных возможностей каждого региона страны (субъекта РФ) с учетом его типологических особенностей.

Максимально эффективное использование конкурентных преимуществ экономического пространства России позволит обеспечить достижение следующих важнейших результатов, вытекающих, в том числе из основных положений Указа Президента РФ № 204 от 07.05.2018 «О национальных целях и стратегических задачах развития Российской Федерации на период до 2024 года»: обеспечение повсеместной доступности основных социальных услуг всему населению страны, независимо от места проживания; сокращение в 2 раза доли населения с доходами ниже величины прожиточного минимума; увеличение удельного веса несырьевого, неэнергетического экспорта более чем в 3,5 раза к 2024 г., в том числе в части продукции высокой степени переработки; обеспечение значительного роста производительности труда (в среднем не менее $5 \%$ прироста); значительное увеличение реальных доходов населения во всех регионах страны; существенное усиление связности экономического пространства России, повышение степени интегрированности экономики различных ее регионов; двукратное увеличение доли малого предпринимательства в ВВП РФ (до $40 \%$ ); значительное смягчение существующих межрегиональных различий в общем уровне экономического развития и экономической активности, а также в уровне и качестве жизни населения [Указ Президента РФ от 01.05.2018 № 204].

Достижение указанных целей и формирование на этой основе условий устойчивого социально-экономического развития России и ее регионов в долгосрочной перспективе предполагает учет воздействия как внешних, так и наиболее значимых вызовов внутреннего характера, сре- 
А.О. Польнев, И.В. Гришина. Методические подходы к построению типологии регионов

ди которых следует выделить: отсутствие тенденции стабильного увеличения численности населения страны при сокращении доли населения в трудоспособном возрасте; продолжающуюся концентрацию населения и его экономической активности в крупнейших агломерациях и городах страны на фоне социально-экономической деградации значительного числа малых городов России, а также сельских населенных пунктов; сохраняющиеся устойчивые межрегиональные контрасты в социально-экономическом развитии Российской Федерации; низкую в целом инфраструктурную обустроенность территории страны, включая наличие обширных зон транспортной недоступности; недостаточный уровень социально-экономического развития большинства геополитически значимых территорий, включая приграничные регионы; неразвитость институтов государственного управления пространственным развитием России, включая неполную проработанность его нормативной правовой базы.

В этой связи одним из важнейших направлений формирования целостной системы государственного регулирования пространственного (регионального) развития страны, исходя из положений Стратегии национальной безопасности РФ [Стратегия ... , 2015], выступает в настоящее время разработка и реализация Стратегии пространственного развития России, одной из ключевых задач которой является «определение с учетом конкурентных преимуществ субъектов РФ их приоритетных экономических специализаций и на этой основе оценка (в территориальном разрезе) перспективных направлений размещения производительных сил, совершенствования системы расселения, потребности в трудовых ресурсах и развития транспортной, энергетической и социальной инфраструктуры, а также приоритетов регионального развития» [Концепция ..., 2017].

Обеспечение эффективного и гармоничного пространственного развития России в долгосрочной перспективе обусловливает необходимость учета специфики различных регионов страны в системе государственного регулирования путем выявления ограниченного числа типов субъектов РФ, для каждого из которых может быть определен особый, специфический комплекс регулятивных воздействий, в том числе мер целевой государственной (федеральной) поддержки.

Представляется очевидным, что конечная результативность разрабатываемой системы государственного регулирования пространствен- ного развития в значительной степени будет обусловлена корректностью определения таких типов (групп) регионов с учетом различных экономических, социальных, природных, геополитических и иных региональных характеристик, а также репрезентативностью применяемой типологии регионов по установленным ключевым признакам.

Под типологией нами понимается отнесение различных регионов страны к однородным группам, выделенным на основе одного или нескольких наиболее существенных критериев, признаков, отношений и уровней организации как количественного, так и качественного характера с целью их идентификации, упорядоченного описания и сопоставления.

Следует подчеркнуть, что принадлежность региона к определенному типу во многом обусловливает модель управления его социальноэкономическим развитием. В связи с этим типологический подход должен стать научной основой для выбора ключевых инструментов регионального управления, опираясь на определенную концептуальную модель развития регионов, включающую представления об их месте в развитии общества, роли в формировании экономического пространства, функциях и закономерностях развития.

К настоящему времени накоплен значительный опыт научных исследований в области построения разнообразных типологий российских регионов, современная значимость которых возрастает в связи с расширением возможностей определения общих принципов государственной региональной политики и ее вариативных механизмов с учетом региональной специфики. Характерным примером использования региональных типологий для целей государственного регулирования может служить типологизация проблемных и кризисных регионов, предложенная А.Г. Гранбергом, которым были, в частности, выделены следующие их качественные признаки: кризисность проявления той или иной крупной проблемы, которая создает угрозу социально-экономическому положению страны, экологическому равновесию, политической стабильности; наличие ресурсного потенциала, использование которого особенно важно для экономики страны; особое значение геополитического и геоэкономического положения региона для стратегических интересов страны; недостаток у региона собственных ресурсов для решения проблем общенационального и мирового значения [Гранберг, 2001]. 
В свою очередь, в рамках исследования, проведенного для регионально-типологического мониторинга экономического и социального развития, В.Е. Шуваловым были выделены следующие четыре основные группы типологий регионов:

- макроструктурная, учитывающая макроструктурную неоднородность страны и производные от нее макроструктурные диспропорции, которые обусловлены фундаментальными природными и историко-географическими факторами;

- экономическая поляризация развития, отражающая высокую степень дифференциации экономического потенциала и уровня экономического развития регионов;

- социальная поляризация развития (дифференциация регионов по уровням социального развития - типологии по Индексу развития человеческого потенциала (Индексу человеческого развития) - и социального расслоения);

- проблемно-структурная типология, отражающая структурно-экономические пропорции и диспропорции регионального социально-экономического развития, выделяющая, в частности, моноотраслевые экспортно-ориентированные, депрессивные старопромышленные регионы с развитым агропромышленным комплексом, формирующие рынок сельскохозяйственной продукции [Шувалов, 2004].

Особое внимание в отечественных исследованиях традиционно уделяется также разработке различных целевых типологий российских регионов. Так, в частности, с позиций исследования инновационных процессов, А.И. Татаркин осуществил типологизацию по концентрации инновационного потенциала, в рамках которой были выделены слудеющие регионы: 1) с высокой концентрацией инновационного потенциала, имеющего международное, региональное и межрегиональное значение, с многоотраслевой экономикой; 2) со средней концентрацией инновационного потенциала, имеющего преимущественно региональное значение, с двумя-тремя градообразующими отраслями; 3) с низкой концентрацией инновационного потенциала, нуждающиеся в инновационной поддержке со стороны государства [Татаркин, 2005].

В свою очередь, В.В. Новохатским территориальные инновационные системы классифицированы с учетом транснациональных, национальных, субъектных, муниципальных и других образований [Новохатский, 2004], а Н.М. Межевич предложил собственную инновационную типологию территорий, выделив в том числе креа- тивные (продвинутые), инновативные (с зарождением и апробацией базисных нововведений), адаптивные (с внедрением инноваций на стадии их массового распространения), а также консервативные (не применяющие инновации) территории [Межевич, 2007].

Пример социально-ориентированной целевой типологии регионов России представлен в работе Н.В. Зубаревича, где в качестве основного критерия выбран уровень развития человеческого потенциала (ИРЧП, Индекс человеческого развития). В рамках его исследования было выделено пять различных типов регионов: наиболее развитые; относительно развитые; средние; с относительно низким уровнем; наиболее отсталые [Зубаревич, 2003].

В ряду работ по типологизации российских регионов следует отметить также труд А.Н. Пилясова, который предлагает выделять внутрирегиональные «малые» экономические районы Алаева-Бекаттини «как основные драйверы современных инновационных преобразований в пространстве России» [Пилясов, 2013].

Наряду с этим в экономической литературе получили распространение также исследования, связанные с построением комплексных типологий регионов с широким набором признаков, объединенных общей задачей представления интегрированной оценки отдельных составляющих социально-экономического развития регионов. Так, например, С.С. Бандманом была разработана расширенная по числу признаков типология регионов, в том числе по уровню накопленного социально-экономического потенциала и степени благосостояния населения, позволившая выделить регионы, соответственно, с высоким, средним и низким уровнем социально-экономического развития [Бандман, 2001]. Значительная часть работ по типологизации регионов нашла отражение в тематическом сборнике, выпущенном под редакцией В.В. Климанова [Типология ..., 2007].

Несмотря на имеющийся опыт научных исследований в части построения типологий российских регионов, единой методики их типологизации для целей государственного регулирования пространственного развития страны к настоящему времени не предложено. На практике для решения различных задач региональной политики применяется множество региональных типологий, построение которых, как правило, подчинено решению той или иной практической задачи.

Вместе с тем явно выраженная пространственная неоднородность России, значительные 
межрегиональные контрасты в экономике и социальной сфере, в уровне экономической активности требуют разработки и использования в системе государственного регулирования пространственного развития, с одной стороны, структурно-отраслевой, и с другой - проблемно-ориентированной типологий субъектов Федерации.

\section{Методологические основы и алгоритм построения структурно-отраслевой типологии регионов}

Как уже отмечалось выше, одним из наиболее распространенных и достаточно обоснованных методов учета региональных особенностей в стратегических документах социально-экономического развития выступает метод группировок на основе выделения типологически однородных групп субъектов РФ, когда вместо бесконечного разнообразия явлений, объектов можно получить ограниченное число их групп. С учетом задач, поставленных Концепцией Стратегии пространственного развития РФ на период до 2025 г. [Концепция ..., 2017], в основе разрабатываемой типологии субъектов Федерации, отражающей их конкурентные преимущества и приоритетные экономические специализации должны лежать особенности их отраслевых структур (структуры видов экономической деятельности), предопределяющие специфику путей обеспечения в долгосрочной перспективе высокой конкурентоспособности и устойчивости развития экономики каждого региона страны.

При разработке структурно-отраслевой типологии и формировании группировок российских регионов важно вместе с тем учитывать, что формируемые по отраслевому принципу типы регионов имеют, в определенной степени, условный характер, ввиду условности соответствующих критериев формирования группировок. В то же время границы типологически однородных групп субъектов РФ являются весьма подвижными, и прежде всего во временном аспекте. Указанную особенность структурно-отраслевой типологии необходимо учитывать в случае намечаемых в долгосрочной перспективе значительных структурных сдвигов в экономике тех или иных регионов.

Порядок идентификации различных типов субъектов Федерации и формирование соответствующих групп должны основываться на использовании специально разработанного алгоритма, а также системы ключевых количественных критериев, определяющих состав и границы типологических групп регионов. При этом в качестве базового методического подхода к разработке алгоритма идентификации типологически однородных групп субъектов Федерации, а также системы исходных критериев отнесения тех или иных регионов к той или иной группе выступает метод экспертных оценок, что обусловливает целесообразность периодического уточнения ключевых характеристик применяемого методического инструментария. Вместе с тем предлагаемый алгоритм определения состава различных групп регионов и последовательного включения в них конкретных субъектов РФ основывается на данных статистической отчетности Росстата в региональном разрезе. В частности, определение структурно различающихся групп регионов рекомендуется осуществлять на базе отчетной информации, представленной в статистическом сборнике «Регионы России. Социально-экономические показатели», а также по данным статистической отчетности по разделу «Национальные счета» (подраздел «Валовой региональный продукт»), в котором приводится структура производства валового регионального продукта (по валовой добавленной стоимости соответствующих видов экономической деятельности), в том числе структура производства промышленной продукции.

Типология регионов РФ по структурноотраслевому признаку должна учитывать следующие современные структурные особенности отечественной экономики и значимые структурно-отраслевые сдвиги как в среднесрочной, так и в долгосрочной перспективе.

Во-первых, в последние два десятилетия проявилась тенденция перехода крупнейших экономических центров страны - г. Москвы и Санкт-Петербурга - к постиндустриальной экономике со специализацией на широком комплексе сферы услуг, при сохранении их лидирующих позиций по важнейшим экономическим и социальным характеристикам.

Во-вторых, в настоящий период в мировой и российской экономике все в большей степени будет проявляться тенденция реиндустриализации, создания новых технологически передовых промышленных и модернизации действующих предприятий, в том числе в традиционных старопромышленных регионах, что предопределяет необходимость выделения в рамках разрабатываемой типологии индустриально-ориентированных субъектов РФ. 
В-третьих, безусловно, важной современной тенденцией изменения позиционирования России в системе мировой экономики выступает ее выход на лидирующие позиции на мировом рынке продукции сельского хозяйства. Данное обстоятельство диктует необходимость идентификации в рамках указанной типологии тех субъектов РФ, которые специализированы и на продукции агропромышленного комплекса.

В-четвертых, совершенно очевидно, что все большее значение в структуре экономики целого ряда российских регионов будет иметь динамично развивающийся туристско-рекреационный комплекс, тесно связанный с развитием и других видов рыночных услуг, включая транспорт и связь, торговлю, гостиничное хозяйство, операции с недвижимостью и др.

Наконец, в-пятых, РФ, безусловно, сохранит и в долгосрочной перспективе свои передовые позиции на мировых рынках топливно-энергетических ресурсов (прежде всего нефти и газа), а также целого ряда иных, особо ценных, минерально-сырьевых ресурсов. Данная ситуация обусловливает необходимость выделения в рамках рассматриваемой структурно-отраслевой типологии также и субъектов Федерации, основу специализации экономики которых составляют отрасли добывающей промышленности, а также регио- нов, специализированных на глубокой переработке добываемых минерально-сырьевых и топливноэнергетических ресурсов.

Рекомендуемый к практическому применению алгоритм идентификации типологически однородных групп регионов в рамках их структурно-отраслевой (структурно-секторальной) типологии основан на последовательном определении групп субъектов Федерации, отличающихся специфическим как современным, так и прогнозируемым на долгосрочную перспективу комплексом специализированных видов экономической деятельности. При этом указанный алгоритм построен на использовании метода последовательного исключения из дальнейшего рассмотрения оцениваемых субъектов Федерации, что позволяет избежать попадания одних и тех же регионов в различные экспертно формируемые группы. Предлагаемая методология построения группировок основана на использовании логических итераций и ряда репрезентативных индикаторов и критериев их оценки, нацеленных на формирование относительно устойчивых типологически однородных групп регионов. При этом, в соответствии с рисунком 1 , могут быть определены семь последовательных итераций построения структурно-отраслевой типологии субъектов РФ [Гришина и др., 2018].

\footnotetext{
1. Постиндустриальные регионы - Доля суммарного объема рыночных услуг в структуре ВРП региона не менее $50 \%$.

Среднедушевой объем ВРП (с учетом уровня покупательной способности) выше аналогичного показателя по РФ
}

\section{2. Энергоресурсные регионы - Доля суммарного объема произ- водства по ВЭД «Добыча полезных ископаемых» и «Производство и распределение электроэнергии, газа и воды» в структуре ВРП региона составляет не менее $50 \%$}

\section{3. Аграрно-индустриальные регионы}

- Доля суммарного объема производства по ВЭД «Сельское хозяйство, охота и лесное хозяйство» и «Рыболовство и рыбоводство» в структуре ВРП региона не менее чем в 2 раза превышает аналогичный показатель по РФ.

- Доля объема производства по ВЭД «Обрабатывающие производства» в структуре ВРП региона составляет от 0,8 до 1,5 значений соответствующей доли по РФ
4. Аграрно-полисервисные регионы

- Доля суммарного объема производства по ВЭД «Сельское хозяйство, охота и лесное хозяйство» и «Рыболовство и рыбоводство» в структуре ВРП региона не менее чем в 2 раза превышает аналогичный показатель по РФ.

- Доля объема производства в субъекте РФ по ВЭД «Обрабатывающие производства» в структуре ВРП региона составляет менее 0,8 значения соответствующей доли по РФ

\section{5. Полисервисные регионы}

- Доля суммарного объема сферы услуг (рыночного и нерыночного сектора) составляет не менее $60 \%$.

- Доля объема производства по виду экономической деятельности «Обрабатывающие производства» в структуре ВРП региона составляет менее $10 \%$
6. Индустриальные ресурсоперерабатывающие регионы Все остальные субъекты РФ, не включенные в состав групп регионов № 1-5 и удовлетворяющие условию: суммарная доля отгрузки товаров собственного производства (выполненных работ, услуг) по видам экономической деятельности «обработка древесины и производство изделий из дерева», «целлюлозно-бумажное производство, издательская и полиграфическая деятельность», «производство кокса и нефтепродуктов, химическое производство, производство резиновых и пластмассовых изделий», «производство прочих неметаллических минеральных продуктов», «металлургическое производство и производство готовых металлических изделий» в общем объеме отгруженных товаров собственного производства (выполненных работ, услуг собственными силами) обрабатывающих производств составляет свыше 65 \%
7. Индустриальноди вер си фи циро ванные регионы

Все остальные субъекты РФ, не включенные в состав групп регионов № 1-6

Рис. 1. Алгоритм построения структурно-отраслевой типологии регионов России

Примечание. Разработано авторами. 
В рамках предлагаемой структурно-отраслевой типологии, отражающей устойчивые секторально-отраслевые особенности регионов России, с учетом их перспективной эффективной специализации в едином экономическом пространстве страны (в том числе, при их объединении в макрорегионы и усилении межрегионального взаимодействия) и расширения возможностей конкурентного позиционирования в системе мировой экономики, нами предлагается выделять следующие основные семь типов регионов (субъектов РФ):

1) постиндустриальные-специализированные на комплексе высокотехнологичных производств с низкой фондоемкостью, широком спектре рыночных, а также образовательных услуг;

2) индустриально-диверсифицированные в основном специализированные на продукции комплекса отраслей обрабатывающей промышленности, включая различные производства в области транспортного, энергетического и технологического машиностроения и металлообработки, приборостроения, электротехнической промышленности, производство строительных материалов, химической, газо- и нефтехимической промышленности, металлургические производства, легкой и фармацевтической промышленности, а также на широком круге рыночных услуг;

3) индустриальные ресурсоперерабатывающие - преимущественно специализированные на комплексе обрабатывающих производств, связанные с переработкой минерально-сырьевых и топливно-энергетических ресурсов;

4) аграрно-индустриальные - специализированные в основном на продукции АПК, рыбохозяйственного комплекса и отдельных отраслей обрабатывающей промышленности, в том числе включая производство машиностроительной продукции для сельского хозяйства, обрабатывающие производства по глубокой переработке сельскохозяйственного сырья, производство минеральных удобрений, строительных материалов для сельских населенных пунктов и др.;

5) аграрно-полисервисные - специализированные преимущественно на продукции АПК и секторе рыночных услуг, включая туристско-рекреационный комплекс;

6) полисервисные (бюджетно-полисервисные) - специализированные в основном на различных видах сферы услуг, включая ее рыночный и нерыночный сектора;

7) энергоресурсные (энергосырьевые) - специализированные на хозяйственном использова- нии природно-ресурсного потенциала, включая добычу и первичную переработку полезных ископаемых, производство и распределение электроэнергии, газа и воды.

При построении группировок следует учитывать, что в экономике каждого субъекта Российской Федерации могут быть представлены также отдельные специализированные виды экономической деятельности, не соответствующие профильному типу данного региона.

Географическая локализация регионов России, сгруппированных по структурно-отраслевому признаку, приводится на рисунке 2.

Следует отметить, что представленная типология российских регионов, несмотря на использование отчетных данных по ключевым структурным индикаторам, на наш взгляд, в значительной степени ориентирована на долгосрочную перспективу, в том числе на период за пределами 2030 года. Выявление принадлежности каждого субъекта Федерации к тому или иному типу регионов в рамках разработки и реализации Стратегии пространственного развития России может быть выполнено на основе комплексной оценки перспектив трансформации региональной хозяйственной структуры с учетом опережающего развития высококонкурентных (на общероссийском и мировом рынках) специализированных видов экономической деятельности с высокой долей добавленной стоимости, а также с учетом возможных перспектив объединения регионов в более крупные пространственные структуры и повышения степени интегрированности экономического пространства России в целом.

Разрабатываемые приоритеты долгосрочного социально-экономического развития для каждого типа регионов должны определяться, исходя из требований повышения степени диверсифицированности структуры региональной экономики за счет увеличения удельного веса наиболее перспективных инновационно-ориентированных видов экономической деятельности, экономически востребованной модернизации предприятий традиционных отраслей, а также обеспечения комплексного и сбалансированного развития отраслей специализации, отраслей, ориентированных на региональный или локальный (муниципальный) товарные рынки и отраслей, финансируемых из бюджетных источников (здравоохранение, образование, государственное и муниципальное управление, социальное обеспечение и др.).

Вместе с тем государственная политика в области социально-экономического развития раз- 
личных типов регионов РФ (в рамках их структурно-отраслевой типологии), повышения эффективности и конкурентоспособности их экономики должна основываться на использовании как общих, так и специфических (территориально-ориентированных) механизмов экономического регулирования пространственного развития.

\section{Основные положения \\ и система критериев построения проблемно-ориентированной типологии регионов}

Сохраняющиеся в России высокий уровень территориальной дифференциации экономического и социального развития страны, крайняя неравномерность распределения по ее территории экономического потенциала обусловливают наличие субъектов РФ, устойчивое развитие которых требует дополнительной федеральной поддержки.

Повышение эффективности и конкурентоспособности экономики таких регионов, создание необходимых условий для их устойчивого социально-экономического развития в долгосрочной перспективе определено общей направленностью государственной политики по обеспечению стратегической конкурентоспособности РФ в глобальной системе мировой экономики.
В настоящий период к регионам (субъектам РФ), в приоритетном порядке требующим дополнительной федеральной поддержки, в соответствии с Концепцией Стратегии пространственного развития Российской Федерации до 2025 г. [Концепция ... , 2017] должны быть отнесены:

1) густонаселенные территории, отстающие по уровню социально-экономического развития и обладающие собственным экономическим потенциалом (І группа);

2) малонаселенные территории, обладающие собственным экономическим потенциалом и/или имеющие существенное значение для обеспечения территориальной целостности страны и безопасности государства (II группа);

3) малонаселенные территории с низким собственным потенциалом экономического роста, имеющие существенное значение для обеспечения территориальной целостности страны и безопасности государства (III группа).

В соответствии с указанным документом [Концепция ..., 2017] для I группы регионов государственная региональная политика будет направлена на обеспечение их опережающего (по сравнению со среднероссийской динамикой) социально-экономического развития, для регионов II и III групп должна обеспечиваться государственная поддержка их необходимого экономического развития и социального обустройства.

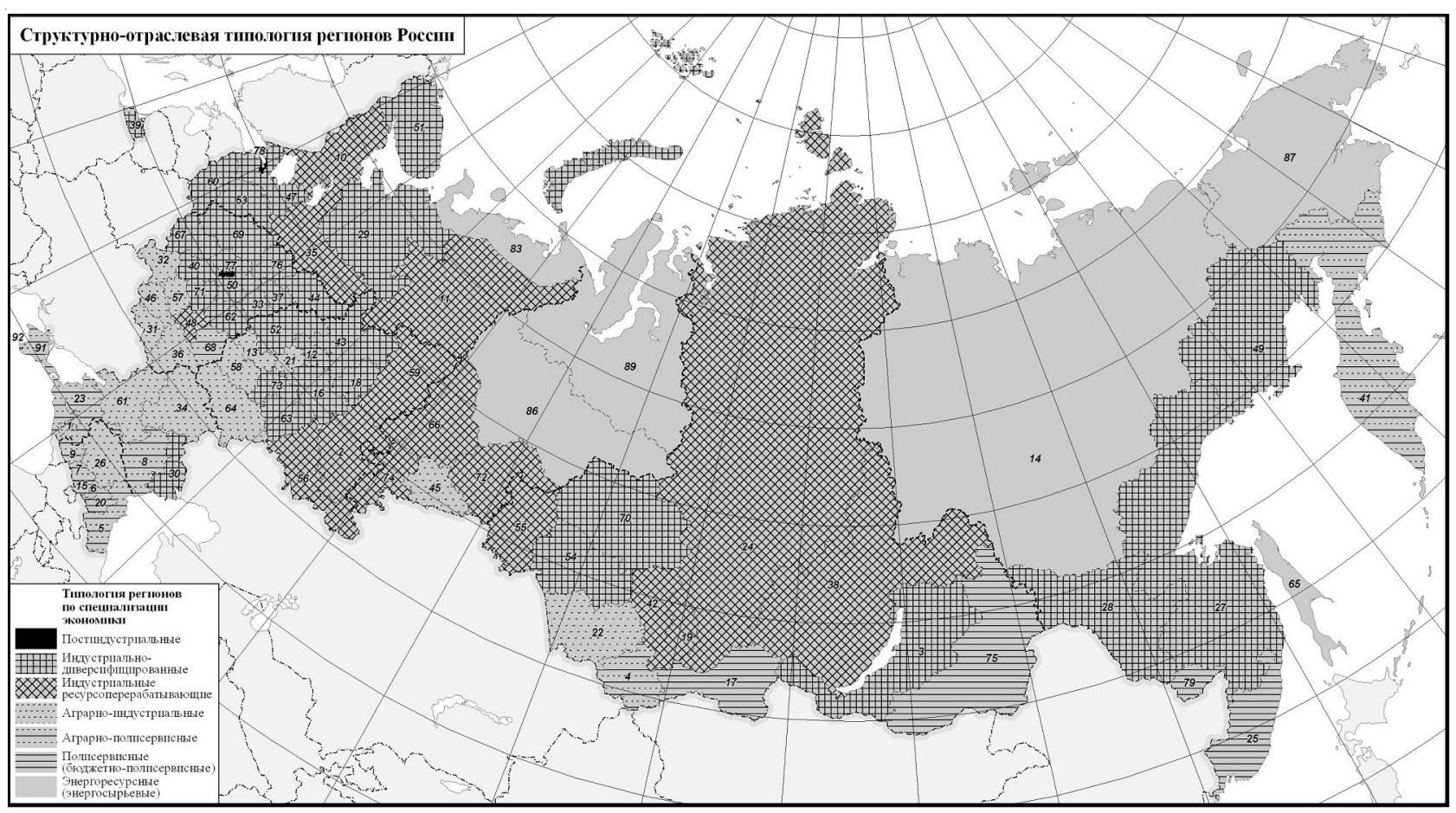

Рис. 2. Структурно-отраслевая типология регионов России

Примечание. Разработано авторами; картограф - канд. географ. наук Д.И. Михайлов 
К числу регионов, имеющих существенное значение для обеспечения территориальной целостности страны и безопасности государства, относятся субъекты РФ, входящие в состав Северо-Кавказского и Дальневосточного федеральных округов, а также Калининградская область, Республика Крым и город федерального значения Севастополь.

Наличие в том или ином регионе собственного экономического потенциала (потенциала экономического роста) может быть отражено выполнением для него как минимум трех из пяти нижеприведенных условий: характеризуется относительно благоприятным геоэкономическим (экономико-географическим) положением; обладает значительной обеспеченностью природноресурсным потенциалом и/или благоприятными природно-климатическими условиями; степень его инфраструктурной обеспеченности (по коэффициенту Энгеля - плотности автомобильных дорог общего пользования с твердым покрытием и железнодорожных путей общего пользования с учетом плотности населения) превышает среднероссийский уровень; суммарная доля занятых в экономике региона с высшим и средним профессиональным образованием насчитывает более $70 \%$; общий объем основных фондов (за вычетом износа) на душу населения составляет более $70 \%$ от среднероссийского уровня.

Сравнительный уровень обеспеченности региона природно-ресурсным потенциалом может быть оценен на основе актуальной стоимостной оценки «востребованного национального богатства недр» [Богатство недр ... , 2008], включая обеспеченность региона основными видами минерально-сырьевых и топливно-энергетических ресурсов (в части оценки в текущих рыночных ценах учтенных остаточных извлекаемых запасов категорий $\mathrm{A}+\mathrm{B}+\mathrm{C} 1+\mathrm{C} 2$ эксплуатируемых в настоящее время месторождений), а также обеспеченность лесными, водными ресурсами, морскими биоресурсами на прилегающей части континентального шельфа, землями сельскохозяйственного назначения. В свою очередь, степень благоприятности природно-климатических условий предлагается оценивать на основе использования экспертных оценок.

С целью учета в рамках предлагаемой проблемно-ориентированной (проблемной) типологии полного круга субъектов РФ, отстающих по уровню социально-экономического развития, в составе группы I в дополнение к густонаселенным территориям (регионам) целесообразно принят в расчет также и средненаселенные регионы с плотностью населения свыше 10 чел. на 1 кв. км.

С учетом этого распределение субъектов РФ по группам I, II и III может быть осуществлено на основе нижеприведенной совокупности критериев. К группе I целесообразно относить густонаселенные и средненаселенные регионы, одновременно удовлетворяющие следующие критерии: ВРП (с учетом уровня покупательной способности) на душу населения составляет не более $65 \%$ от среднероссийского уровня (в среднем за 3 последних отчетных года); плотность населения насчитывает более 10 чел. на 1 кв. км; имеется собственный экономический потенциал (потенциал экономического роста).

Во II группу включаются малонаселенные (в том числе геополитически значимые) регионы, соответствующие следующим критериям: плотность населения насчитывает не более 10 чел. на 1 кв. км; имеется собственный экономический потенциал (потенциал экономического роста).

К группе III относятся малонаселенные (в том числе геополитически значимые) регионы, которые удовлетворяют следующие критерии: ВРП (с учетом уровня покупательной способности) на душу населения составляет менее $65 \%$ от среднероссийского уровня (в среднем за 3 последних отчетных года); плотность населения региона насчитывает не более 10 чел. на 1 кв. км; отсутствует достаточный собственный экономический потенциал (крайне низкий потенциал экономического роста).

Использование проблемно-ориентированной типологии, а также других аналогичных типологий российских регионов, в том числе характеризующих их сравнительное социально-экономическое положение [Гришина, Полынев, Максимов, 2009], при разработке и реализации Стратегии пространственного развития страны на долгосрочную перспективу позволит обеспечить сбалансированное, комплексное развитие всех субъектов РФ, расширить и укрепить хозяйственные связи между ними, а также сформировать действенный механизм сокращения уровня межрегиональной социально-экономической дифференциации путем сбалансированного территориального развития России, устранения инфраструктурных ограничений, ввести механизм координации размещения транспортной, инженерной и социальной инфраструктур всех уровней.

В то же время предлагаемый алгоритм построения обеспечивает для большинства субъек- 
тов РФ, которые вносят основной вклад в экономику страны, четкое позиционирование за рамками проблемно-ориентированной типологии, оставляя тем самым большие шансы на федеральную поддержку другим регионам, действительно проблемным и в ней нуждающимся.

Итоговые результаты построенной с использованием предлагаемых подходов двухмерной классификации, отражающие как структурно-отраслевую, так и проблемную типологию субъектов Федерации, приводятся в таблице 1. Как следует из результатов, проведенных по данным расчетов за 2014-2016 гг., к числу проблемных (включая геополитически значимые) регионов в настоящий период не относятся только субъекты РФ, являющиеся по структурно-отраслевому признаку постиндустриальными или индустриальными ресурсоперерабатывающими.
Вместе с тем существенное отставание в использовании собственного экономического потенциала наблюдается не только в ряде ключевых регионов Сибири, Дальнего Востока и Юга России (относящихся к территории Южного и Северо-Кавказского федеральных округов), но и в значительном числе регионов Центра европейской России, а также Поволжья, преимущественно являющихся индустриально-диверсифицированными или аграрно-индустриальными субъектами РФ.

Полученные результаты проведенного исследования подтверждают необходимость комплексного подхода к разработке и практической реализации системы государственной федеральной поддержки обеспечения устойчивого экономического и социального развития российских регионов на долгосрочную перспективу.

Таблийа 1

Результаты двухмерной классификации регионов России (2014-2016 гг.)

\begin{tabular}{|c|c|c|c|c|}
\hline \multirow{3}{*}{$\begin{array}{l}\text { Структурно-от- } \\
\text { раслевая типо- } \\
\text { логия регионов }\end{array}$} & \multicolumn{4}{|c|}{ Проблемная типология регионов } \\
\hline & \multirow{2}{*}{$\begin{array}{l}\text { 1. Густонаселенные } \\
\text { и средненаселенные) } \\
\text { территории, отстающие } \\
\text { в уровне социально- } \\
\text { экономического разви- } \\
\text { тия и обладающие соб- } \\
\text { ственным экономиче- } \\
\text { ским потенциалом (опе- } \\
\text { режающие развитие) }\end{array}$} & \multicolumn{2}{|c|}{$\begin{array}{l}\text { Малонаселенные регионы (включая } \\
\text { геополитически значимые террито- } \\
\text { рии), имеющие существенное значе- } \\
\text { ние для обеспечения территориаль- } \\
\text { ной целостности РФ и безопасности } \\
\text { государства }\end{array}$} & \multirow[b]{2}{*}{$\begin{array}{c}\text { Регионы, не относящиеся } \\
\text { к группам I-III }\end{array}$} \\
\hline & & $\begin{array}{lr}2 . & \text { Обладающие } \\
\text { собственным } & \text { эко- } \\
\text { номическим } & \text { по- } \\
\text { тенциалом } & \text { (эко- } \\
\text { номическое разви- } \\
\text { тие и социальное } \\
\text { обустройство) }\end{array}$ & $\begin{array}{l}\text { 3. С низким соб- } \\
\text { ственным потен- } \\
\text { циалом экономи- } \\
\text { ческого роста } \\
\text { (необходимое } \\
\text { социальное обу- } \\
\text { стройство) }\end{array}$ & \\
\hline $\begin{array}{l}\text { 1. Постиндуст - } \\
\text { риальные }\end{array}$ & - & 年 & 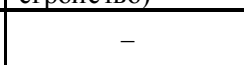 & г. Москва, г. Санкт-Пет ербург \\
\hline $\begin{array}{l}2 . \text { Индустр иаль- } \\
\text { ноди версифици- } \\
\text { рован ные }\end{array}$ & $\begin{array}{l}\text { Республика Марий Эл; } \\
\text { Тверская, Владимирская, } \\
\text { Ивановская, Костромская, } \\
\text { Ульяновская, Смоленская, } \\
\text { Псковская, Кировская об- } \\
\text { ласти }\end{array}$ & $\begin{array}{l}\text { Бурятия; Хабаров- } \\
\text { ский край; Амур- } \\
\text { ская, Магаданская } \\
\text { области }\end{array}$ & - & $\begin{array}{l}\text { республики Татарстан, Удмуртия; Рязан- } \\
\text { ская, Калужская, Калининградская, Мос- } \\
\text { ковская, Ярославская, Архангельская, Том- } \\
\text { ская, Тульская, Ленинградская, Мурман- } \\
\text { ская, Самарская, Новгородская, Астрахан- } \\
\text { ская, Нижегородская, Новосибирская облас- } \\
\text { ти }\end{array}$ \\
\hline $\begin{array}{l}\text { 3. Индустр иаль- } \\
\text { ные ресурсопе- } \\
\text { рерабатывающие }\end{array}$ & - & - & - & $\begin{array}{l}\text { республики Карелия, Коми, Башкортостан, } \\
\text { Хакасия; Красноярский, Перм ский края; } \\
\text { Липецкая, Вологодская, Оренбургская, } \\
\text { Свердловская, Тюменская, Челябинская, } \\
\text { Иркутская, Кемеровская, Омская области }\end{array}$ \\
\hline $\begin{array}{l}\text { 4. Аграрно-инду- } \\
\text { стриальные }\end{array}$ & $\begin{array}{l}\text { Мордовия, Чувашия, Ады- } \\
\text { гея; Ставропольский, Ал- } \\
\text { тайский края; Курганская, } \\
\text { Ростовская, Брянская, Пен- } \\
\text { зенская области }\end{array}$ & - & - & $\begin{array}{l}\text { Белгородская, Воронежская, Волгоградская, } \\
\text { Сарат овская, Курская, Орло вс кая област и }\end{array}$ \\
\hline $\begin{array}{l}\text { 5. Аграрно-поли- } \\
\text { сервисные }\end{array}$ & $\begin{array}{l}\text { республики Крым, Даге- } \\
\text { стан, Кабардино-Балкария, } \\
\text { Карачаево-Черкеси я, Се- } \\
\text { верная Осетия - Алания }\end{array}$ & $\begin{array}{lr}\text { Республика } & \text { Калмы- } \\
\text { кия; } & \text { Камчатский } \\
\text { край } & \end{array}$ & $\begin{array}{ll}\text { Республика } & \text { Ал- } \\
\text { тай }\end{array}$ & Краснодарский край; Тамбовская область \\
\hline $\begin{array}{l}6 . \quad \text { Полисервис- } \\
\text { ные (бюджет но- } \\
\text { полисервисные) }\end{array}$ & $\begin{array}{l}\text { г. Севастополь; республи - } \\
\text { ки Ингушетия, Чечен ская }\end{array}$ & $\begin{array}{l}\text { Забайкальский край; } \\
\text { Еврейская автоном- } \\
\text { ная область }\end{array}$ & Республика Тыва & Прим орский край \\
\hline $\begin{array}{l}\text { 7. Энерг оресурс- } \\
\text { ные (эн ергосырь- } \\
\text { евые) }\end{array}$ & - & 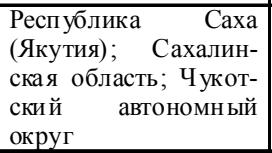 & - & $\begin{array}{l}\text { Ненецкий, Ханты-Мансийский }- \text { Югра, } \\
\text { Ямало-Нен ецкий автономный округа }\end{array}$ \\
\hline
\end{tabular}

Примечание. Разработано авторами. 
Заключение

Предложенные методические подходы к построению структурно-отраслевой и проблемно-ориентированной типологий субъектов РФ для целей разработки Стратегии пространственного развития России носят открытый характер и могут быть в дальнейшем уточнены и конкретизированы с учетом накопленного практического опыта их последующего использования в системе региональных (пространственных) исследований в части как используемых критериальных экономических индикаторов, так и применяемого инструментария проводимой оценки.

В рамках разработки Стратегии пространственного развития России на долгосрочный период, с учетом типологических особенностей выделенных регионов, целесообразно определение состава согласованных отраслевых приоритетов развития для каждого субъекта РФ, исходя из целевых установок, отраженных в документах стратегического планирования федерального уровня, включая основы государственной политики регионального развития, отраслевых стратегий, стратегий социально-экономического развития федеральных округов и др.), а также в стратегических документах регионального уровня, региональных инвестиционных стратегиях, стратегиях кластерного (отраслевого) развития и других.

Сформированная в региональном разрезе многоуровневая система отраслевых приоритетов социально-экономического развития России может быть использована при обосновании направлений развития территориальной структуры общероссийской экономики на долгосрочную перспективу.

\section{СПИСОК ЛИТЕРАТУРЫ}

Бандман С. С., 2001. Экономика республик РФ. Кризис и трансформационные процессы в 80-90 годах XX века : монография. Элиста : Джангар, 2001. $212 \mathrm{c}$.

Богатство недр России: минерально-сырьевой и стоимостной анализ, 2008. Изд. 3-е, доп. СПб. : Всеросс. науч.-исслед. геолог. ин-т им. А.П. Карпинского. $483 \mathrm{c}$.

Гранберг А. Г., 2001. Стратегия территориального социально-экономического развития России: от идеи к реализации // Вопросы экономики. № 9. C. 15-27.

Гришина И. В., Полынев А. О., Максимов И. С., 2009. Социально-экономическое положение регионов
России: опыт оперативной сравнительной оценки // Инвестиции в России. № 7. С. 6-13.

Гришина И. В., Полынев А. О., Шкуропат А. В., Котов А. В., 2018. Стратегия пространственного развития России: методические подходы к разработке экономического блока : монография / под ред. дра экон. наук И. В. Гришиной. М. : ВАВТ. 280 с.

Зубаревич Н. В., 2003. Социальное развитие регионов России: проблемы и тенденции переходного периода. М. : УРСС, 2003. $261 \mathrm{c.}$

Концепщия стратегии пространственного развития Российской Федерации на период до 2030 года, 2016. M. : МЭР РФ. 111 c. URL: http://карьеры-евразии.рф/uploadedFiles/files/Kontseptsiya_SPR.pdf.

Межевич Н. М., 2007. Механизм влияния международного сотрудничества на инновационное развитие регионов // Экономика и управление. № 6. С. 63-65.

Новохатский В. В., 2004. Определение и классификация инновационных систем // Инновации. № 9. C. 5-6.

Пилясов А. Н., 2013. Контуры новой теории экономического районирования России (основные элементы) // Современная регионалистика: структура, проблемы, перспективы. СПб. : Изд-во СПбГЭУ. С. 31-44.

Стратегия национальной безопасности Российской Федерации : утв. указом Президента РФ от 31.12.2015 № 683 «О Стратегии национальной безопасности Российской Федерации». Доступ из справ.-правовой системы «КонсультантПлюс».

Татаркин А. И., 2005. Формирование инновационных территорий в контексте проблем технологической модернизации экономики // Инновации. № 7. C. 26-30.

Типология субъектов Российской Федерации с точки зрения регионального развития, 2007 / под ред. В. В. Климанова. М. : ИРОФ. 209 с.

Указ Президента Российской Федерации от 07.05.2018 № 204 «О национальных целях и стратегических задачах развития Российской Федерации на период до 2024 года» URL: http://kremlin.ru/acts/ bank/43027.

Шувалов В. Е., 2004. Экономико-географическое районирование в контексте модернизации российского общества // Институциональная модернизация российской экономики: территориальный аспект / отв. ред. А. Г. Дружинин, В. Е. Шувалов. Ростов н/Д : Изд-во Рост. ун-та. С. 72-187.

\section{REFERENCES}

Bandman S.S., 2001. Ekonomika respublik RF. Krizis $i$ transformatsionnye protsessy $v$ 80-90 godax $X X$ veka: monografiya [Economics of Republics of the Russian Federation. Crisis and Transformation Processes in 1980-1990s: Monograph]. Elista, Dzhangar Publ. 212 p. 
Bogatstvo nedr Rossii.Mineralno-syrevoy i stoimostnoy analiz, 2008 [Subsoil Wealth of Russia. Mineral and Valuation Analysis, 2008]. Saint Petersburg, All-Russian Research Geological Institute A.P. Karpinsky Publ. 483 p.

Granberg A.G., 2001. Strategiya territorialnogo sotsialnoekonomicheskogo razvitiya Rossii: ot idei k realizatsii [Territorial Strategy for Socio-Economic Development of Russia: From the Idea to Realization]. Voprosy ekonomiki [Questions of Economy], no. 9, pp. 15-27.

Grishina I.V., Polynev A.O., Maksimov I.S., 2009. Sotsialno-ekonomicheskoe polozhenie regionov Rossii: opyt operativnoy sravnitelnoy otsenki [Socio-Economic Situation of the Regions of Russia: Experience of Operational Comparative Assessment]. Investitsii $v$ Rossii [Investment in Russia], no. 7, pp. 6-13.

Grishina I.V., Polynev A.O., Shkuropat A.V., Kotov A.V., 2018. Strategiya prostranstvennogo razvitiya Rossii: metodicheskie podkhody $k$ razrabotke ekonomicheskogo bloka: monografiya [Spatial Development Strategy of Russia: Methodological Approaches to the Development of the Economic Block: Monograph]. Moscow, Russian Foreign Trade Academy Publ. 280 p.

Zubarevich N.V., 2003. Sotsialnoe razvitie regionov Rossii: problemy $i$ tendentsii perekhodnogo perioda [Social Development of the Regions of Russia: Problems and Trends in Transition]. Moscow, URSS Publ., 2003. 261 p.

Kontseptsiya strategiya prostranstvennogo razvitiya Rossiyskoy Federatsii do 2030 goda, 2016 [The Concept of Spatial Development Strategy of the Russian Federation Up to the Year 2030, 2016]. Moscow, Ministry of Economic Development of the Russian Federation. 111 p. URL: http://карьеры-евразии.pф/uploadedFiles/files/Kontseptsiya_SPR.pdf.

Mezhevich N.M., 2007. Mekhanizm vliyaniya mezhdunarodnogo sotrudnichestva na innovatsionnoe razvitie regionov [Effect Mechanism of International Cooperation for Innovative Development of Regions]. Ekonomika $i$ upravlenie [Economics and Management], no. 6, pp. 63-65.

Novokhatskiy V.V., 2004. Opredelenie i klassifikatsiya innovatsionnykh sistem [Definition and Classification of Innovation Systems]. Innovatsii [Innovations], no. 9, pp. 5-6.
Pilyasov A.N., 2013. Kontury novoy teorii ekonomicheskogo rayonirovaniya Rossii (osnovnye elementy) [Contours of the New Theory of Economic Zoning of Russia (Basic Elements)]. Sovremennaya regionalistika: struktura, problemy, perspektivy [Modern Regional Science: Structure, Problems, Prospects]. Saint Petersburg, Saint Petersburg State University of Economics Publ., pp. 31-44.

Strategiya natsionalnoy bezopasnosti Rossiyskoy Federatsii: utverzhdena ukazom Prezidenta Rossiyskoy Federatsii ot 31.12.2015 № 683, 2015 [The National Security Strategy of the Russian Federation: Approved by Decree of the President of the Russian Federation of December 31, 2015 No. 683]. Access from Reference Legal System "KonsultantPlyus"

Tatarkin A.I., 2005. Formirovanie innovatsionnykh territoriy $\mathrm{v}$ kontekste problem tekhnologicheskoy modernizatsii ekonomiki [Forming Innovative Territories in the Context of the Technological Modernization of the Economy]. Innovatsii [Innovations], no. 7, pp. 26-30.

Klimanov V.V., ed., 2007. Tipologiya subyektov Rossiyskoy Federatsii s tochki zreniya regionalnogo razvitiya [Typology of the Constituent Entities of the Russian Federation in Terms of Regional Development]. Moscow, Institute of Public Finance Reform Publ. 209 p.

Ukaz Prezidenta Rossiyskoy Federatsii ot 07.05.2018 g. № 204 «O natsionalnykh tselyakh $i$ strategicheskikh zadachakh razvitiya Rossiyskoy Federatsii na period do 2024 goda», 2018 [Decree of the President of the Russian Federation of May 7, 2018 No. 204 "On National Objectives and Strategic Tasks of the Development of the Russian Federation for the Period until 2024"]. URL: http:// kremlin.ru/acts/bank/43027.

Shuvalov V.E., 2004. Ekonomiko-geograficheskoe rayonirovanie $\mathrm{v}$ kontekste modernizatsii rossiyskogo obshchestva [Economic and Geographical Regionalization in the Context of the Modernization of the Russian Society]. Druzhinin A.G., Shuvalov V. E., eds. Institutsionalnaya modernizatsiya rossiyskoy ekonomiki: territorialny aspekt [Institutional Modernization of the Russian Economy: the Territorial Aspect]. Rostov-on-Don, Rostov University Publ., pp. 72-187. 


\section{Information about the Authors}

Andrey O. Polynev, Doctor of Sciences (Economics), Deputy Director of Department of Theory and Methodology of Spatial Studies, Council for the Study of Productive Forces, Russian Foreign Trade Academy at the Ministry of Economic Development of the Russian Federation, Pudovkina St., 4A, 119285 Moscow, Russian Federation; Leading Researcher, Institute of Industry Markets and Infrastructure, Russian Presidential Academy of National Economy and Public Administration, Prosp. Vernadskogo, 82, bld. 1, 119571 Moscow, Russian Federation, apolynev@yandex.ru, https://orcid.org/0000-0003-4850-2950

Irina V. Grishina, Doctor of Sciences (Economics), Deputy Chairman of the Council for the Study of Productive Forces, Russian Foreign Trade Academy at the Ministry of Economic Development of the Russian Federation, Pudovkina St., 4A, 119285 Moscow, Russian Federation; Leading Researcher, Institute of Industry Markets and Infrastructure, Russian Presidential Academy of National Economy and Public Administration, Prosp. Vernadskogo, 82, bld. 1, 119571 Moscow, Russian Federation, grishinaiv@mail.ru, https://orcid.org/00000003-0743-7232

\section{Информация об авторах}

Андрей Олегович Полынев, доктор экономических наук, заместитель руководителя отделения теории и методологии пространственных исследований Совета по изучению производительных сил, Всероссийская академия внешней торговли Минэкономразвития России, ул. Пудовкина, 4А, 119285 г. Москва, Российская Федерация; ведущий научный сотрудник Института отраслевых рынков и инфраструктуры, Российская академия народного хозяйства и государственной службы, просп. Вернадского, 82, стр. 1, 119571 г. Москва, Российская Федерация, apolynev@yandex.ru, https://orcid.org/00000003-4850-2950

Ирина Владимировна Гришина, доктор экономических наук, заместитель Председателя Совета по изучению производительных сил, Всероссийская академия внешней торговли Минэкономразвития России, ул. Пудовкина, 4А, 119285 г. Москва, Российская Федерация; ведущий научный сотрудник Института отраслевых рынков и инфраструктуры, Российская академия народного хозяйства и государственной службы, просп. Вернадского, 82, стр. 1, 119571 г. Москва, Российская Федерация, grishinaiv@mail.ru, https://orcid.org/0000-0003-0743-7232 